\title{
Dextrose Prolotherapy in the Treatment of Recurrent Temporomandibular Joint Dislocation (clinical study)
} Original Article

\author{
Alaa A. Saadat, Mohamed S. Khedr, Khalid A. Saad, Ahmed S. Naguib \\ Oral and Maxillofacial Surgery Department, Faculty of Dentistry, Tanta University
}

\begin{abstract}
Purpose: compare between injections of dextrose prolotherapy in two different sites in the treatment of recurrent temporomandibular joint dislocation.

Patient \& Methods: A prospective, randomized clinical study on 16 patients suffering from recurrent temporomandibular joint dislocation was assigned into two equal groups. Group I was treated using dextrose prolotherapy ( $2 \mathrm{ml}$ of $25 \%$ dextrose solution) injected into retro-discal ligament and Group II was treated using dextrose prolotherapy injected into superior joint space. All patients were examined radiographically by $\mathrm{CT}$ scan preoperatively to exclude any case with TMJ pathosis. Preoperative and postoperative clinical evaluation all over 6 months follow up periods for maximal mouth opening, visual analogue scale and frequency of dislocation were done for all patients of both groups. The collected data were then statistically analyzed.
\end{abstract}

Results: $75 \%$ of all patients were treated with only single injection. There was no statistically significant difference between the two groups regarding to maximal mouth opening, in both groups, showed decrease in maximal mouth opening which resolved after 1 month follow up. Both groups showed maximal peek of pain according to visual analogue scale in first 2 weeks with more pain in group II. There was no significant difference between the two groups regarding frequency of dislocation.

Conclusion: dextrose prolotherapy is an effective minimally invasive method in the treatment of recurrent temporomandibular joint dislocation by strengthen the lax ligaments and decrease frequency of TMJ dislocation, with no significant difference between the two groups except regarding more pain and discomfort after injection in group II.

Key Words: Dextrose; temporomandibular joint dislocation;treatment

Received: 08 September 2018, Accepted: 24 November 2018

Corresponding Author: Alaa A. Saadat, Instructor Oral \& Maxillofacial Surgery Department, Faculty of Dentistry, Tanta University, Egypt, E-mail: silver.wisdom.tooth@gmail.com

ISSN: 2090-097X, October 2018, Vol. 9, No. 4

\section{INTRODUCTION:}

Many patients have recurrent dislocation of the temporomandibular joint (TMJ), which may occur during ordinary activities such as yawning and laughing. In anterior TMJ dislocation the mandibular condyle becomes displaced from the glenoid fossa and is locked anterior to the articular eminence. This leads to discomfort, inability to close the mouth. TMJ dislocation classified depending on the onset and frequency of dislocation to acute, chronic recurrent or subluxation or according to the direction of dislocated condyle to superior, medial, lateral, anterior or posterior dislocation which can occur bilateral, or unilateral $^{[1]}$.

Several techniques have been advocated for the treatment of chronic TMJ dislocation. Non-surgical approaches have been proposed to prevent the excessive abnormal excursions of the condyle including bandages and splints $^{[2]}$. Minimally invasive methods used in the treatment of chronic TMJ dislocation are injection of sclerosing agent $t^{[3]}$, or autogenous blood into TMJ which aimed to induce fibrosis and limit the condylar movement but with drawbacks of unexpected reduction of mouth opening $^{[4-6]}$. Also Oztel et al., (2017) ${ }^{[7]}$ used injection of Botulinum toxin into lateral pterygoid muscle as a treatment modality for recurrent TMJ dislocation to restrict condylar movement anteriorly and prevent dislocation.

Different surgical methods for treatment of recurrent TMJ dislocation were used includeing eminectomy ${ }^{[8]}$ to remove the anterior stop of condyle and permit the condyle to move freely as in the research of and augmentation eminoplasty ${ }^{[9,10]}$ aiming to augment articular eminence by either mini plates or bone to prevent anterior TMJ dislocation.

Proliferation treatment, or "Prolotherapy,"is also known as regenerative injection therapy Prolotherapy involves injecting a non-pharmacological irritant solution such as dextrose into the region of the tendons or ligaments, and 
it is hypothesized that it initiates an inflammatory process that deposits new additional fibers that will strengthen the laxed tendons or ligaments and possibly promote the release of local growth factors ${ }^{[1]}$.

Traditional prolotherapy of the TMJ requires injections at several sites, including the superior joint space and it is a skilled technique that requires specialized training, also it has drawbacks of severe pain and reduces maximum mouth opening $^{[12]}$. Zhou et al., (2014) $)^{[13]}$ adopt new injection technique in which we inject in retro-discal tissue and avoid injection in joint space. In this study we compare this new injection site with the standard superior joint space injection prolotherapy in the treatment of recurrent TMJ dislocation.

\section{PATIENTS AND METHOD}

Prospective case series study that was conducted on sixteen patients with bilateral recurrent dislocation of the TMJ. The study was done at Oral and Maxillofacial Surgery Department Faculty of Dentistry Tanta University. The patients were divided randomly into two equal groups. The criteria for inclusion in this study were adult patients between twenty and fourty years old with recurrent dislocation of TMJ more than two times in the last month. The criteria for exclusion were patients with neurological

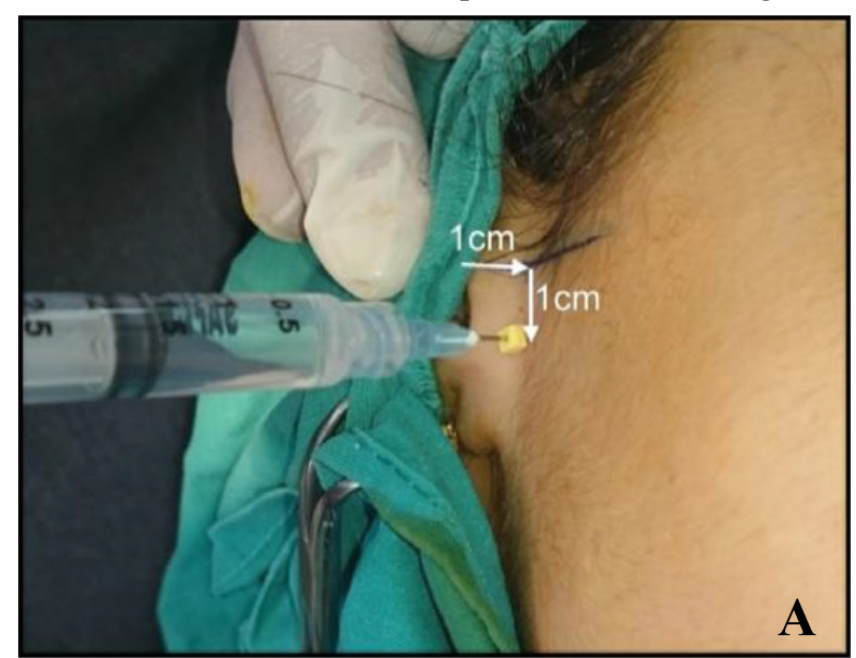

conditions, parafunctional habits, allergic to lidocaine and dextrose, Ehler Danlos syndrome or Patients taking anticoagulant drugs.

\section{Injection Technique:}

\section{Group (I):}

The skin surface of the preauricular area was disinfected with betadine surgical scrub solution. A line was drawn on the skin of the face from the tragus of the ear to the outer canthus of the eye. A first point was marked $10 \mathrm{~mm}$ anterior to the tragus of the ear along the tragocanthal line and then a second point was marked $10 \mathrm{~mm}$ inferior to the first point on line perpendicular to the tragocanthal line.

Auriculotemporal nerve block ${ }^{[14,15]}$ was achieved using $2 \mathrm{ml}$ of $2 \%$ lidocain local anesthetic solution. After the local anesthesia was obtained prolotheraby was done by injecting $2 \mathrm{ml}$ of $25 \%$ dextrose solution. The needle was directed to the surface of the condylar neck till the depth of $5 \mathrm{~mm}$ and $0.5 \mathrm{ml}$ was deposited, then the needle was advanced along the back of condyle to a depth of $25 \mathrm{~mm}$, where $0.5 \mathrm{ml}$ was deposited. The needle then withdrawn $5 \mathrm{~mm}$ and the remaining $1.0 \mathrm{ml}$ were gradually injected. The depth of needle penetration in the tissue was controlled using rubber stopper on the syringe needle. (Fig. 1)

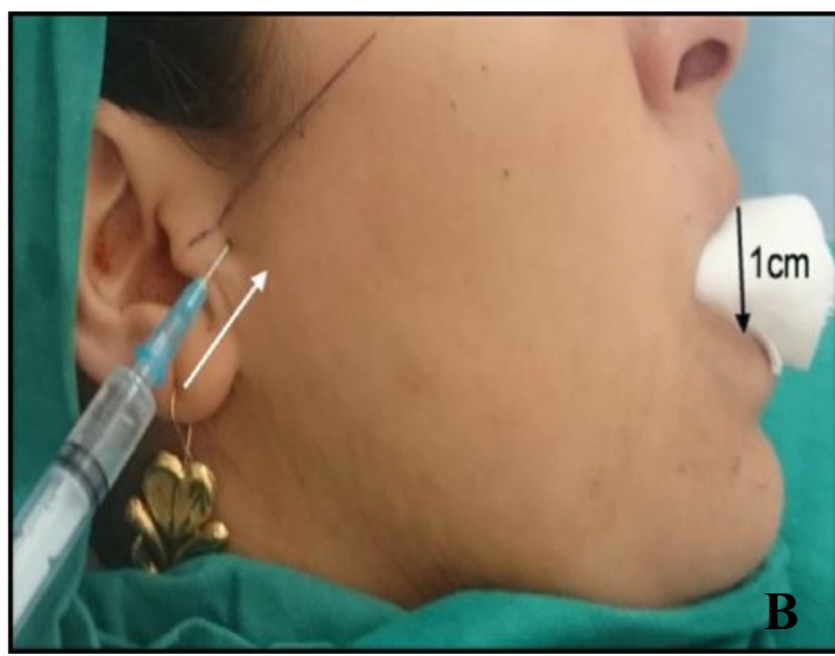

Fig. 1: A showing injection of case No. (1) group (I) with $2 \mathrm{ml}$ of $25 \%$ dextrose prolotheraby at retrodiscal tissue $b$ showing case No. (5) group (II) biting on cotton roll about $1 \mathrm{~cm}$ thickness and injection with $2 \mathrm{ml}$ of $25 \%$ dextrose prolotherapy with the needle advanced superiorly, anteriorly and medially for injection in the superior joint space

\section{Group (II):}

The skin surface of the preauricular area was disinfected with betadine surgical scrub solution. Local anesthesia to the skin was obtained with infiltration technique by $2 \mathrm{ml}$ of lidocaine $2 \%$. Access to the superior joint space was attained by asking the patient to close the anterior teeth on a small bite block or $1 \mathrm{~cm}$ thickness of dental cotton rolls which enables translation of the mandibular condyles down the anterior slope of the glenoid fossa. The point of needle insertion was marked on the skin with indelible pencil midway between tragus of ear and posterior aspect of condyle. The syringe needle was directed superiorly and anteriorly towards the apex of the glenoid fossa into the superior joint space until contact of the needle with the periosteum was reached. $2 \mathrm{ml}$ of $25 \%$ dextrose solution was gradually injected in the superior joint space ${ }^{[16,17]}$.(Fig. 1)

\section{Post-operative instructions:}

The patients were instructed to eat soft diet and avoid wide mouth opening ${ }^{[12,13]}$, ice application after injection and anti-inflammatory drugs for 2 weeks. Acetaminophen ${ }^{[1]}$ was prescribed for pain control after injection if needed ${ }^{[18]}$.

The patients from both groups were evaluated clinically at intervals 2 weeks, 1 month, 3 months and 6 months post injection regarding Maximal mouth opening (MMO) as the distance in centimeters between the incisal edges of the 
upper and lower incisors, Presence of pain upon opening was recorded (VAS) and Frequency of dislocation per week.

\section{RESULTS}

This study was conducted on 16 adult patients with recurrent TMJ dislocation 5 patients were males (31.25\%) and 11 patients were females $(68.75 \%)$ divided into two groups. Group (I) 3 patients were males $(37.50 \%)$ and 5 patients were females $(62.50 \%)$ the patient's ages ranged from 20 to 36 years old in with a mean of 29.125. Group (II) 2 patients were males $(25 \%)$ and 6 patients were females (75\%) the patient's ages ranged from 23 to 40 with mean of 29.5 .

Visual Analogue Scale (VAS): was measured for all patients in both groups at each follow up periods shows only pain at 2 weeks follow up interval. Group (I) range from 57- with one patient (12.5\%) scored 7, two patients $(25 \%)$ scored 6.5, one patent (12.5) scored 6, two patients (25\%) scored 5.5 and two patients $(25 \%)$ scored 5 on VAS with mean of 5.87 and standard deviation of 0.79 with maximal peek of pain reported at first two days post injection. Group (II) range from 6.58-. Two patients (25\%) scored 8, three patients $(37.5 \%)$ scored 7.5 , two patients $(25 \%)$ scored 7 and one patient $(12.5 \%)$ scored 6.6 on VAS with mean of 7.37 and standard deviation of 0.64 with maximal peek of pain reported at first two days post injection. There was statistically significant difference between the two groups at level of 0.001 as $p$ value $\leq 0.05$ with more pain in group (II).

Both groups showed statistically significant difference between pre injection and two weeks follow up which indicate significant reduction in maximal mouth opening. There was no statistically significant difference between the two groups at two weeks follow up periods. But there was no statistically significant difference between pre injection and six months follow up in both group which indicate the reduction in MMO which happened after injection was recovered. (Table 1)

Table 1: Showing statistical analysis for maximal inter incisal mouth opening in both groups.

\begin{tabular}{|c|c|c|c|c|c|c|c|c|c|c|}
\hline \multirow{2}{*}{\multicolumn{3}{|c|}{ MMO }} & \multicolumn{6}{|c|}{ Groups } & \multicolumn{2}{|c|}{ T-Test } \\
\hline & & & \multicolumn{3}{|c|}{ Group I } & \multicolumn{3}{|c|}{ Group II } & \multirow{2}{*}{$\frac{\mathrm{t}}{1.050}$} & \multirow{2}{*}{$\frac{P \text {-value }}{0.311}$} \\
\hline \multicolumn{2}{|c|}{ Pre } & Range & 4 & - & 4.7 & 3.8 & - & 5 & & \\
\hline & & Mean \pm SD & 4.325 & \pm & 0.260 & 4.150 & \pm & 0.393 & & \\
\hline \multicolumn{2}{|c|}{2 Weeks } & Range & 3 & - & 4 & 3.3 & - & 4.1 & -0.550 & 0.592 \\
\hline & & Mean \pm SD & 3.613 & \pm & 0.323 & 3.700 & \pm & 0.289 & & \\
\hline \multicolumn{2}{|c|}{1 Month } & Range & 3.5 & - & 4.2 & 3.4 & - & 4.3 & 0.878 & 0.396 \\
\hline & & Mean \pm SD & 3.875 & \pm & 0.260 & 3.729 & \pm & 0.382 & & \\
\hline \multicolumn{2}{|c|}{3 Months } & Range & 3 & - & 4.5 & 3.4 & - & 4.2 & -0.022 & 0.983 \\
\hline & & Mean \pm SD & 3.929 & \pm & 0.450 & 3.933 & \pm & 0.301 & & \\
\hline \multicolumn{2}{|c|}{6 Months } & Range & 3 & - & 4.5 & 3.5 & - & 4 & 0.456 & 0.657 \\
\hline & & Mean \pm SD & 3.929 & \pm & 0.450 & 3.833 & \pm & 0.258 & & \\
\hline P-2W & Differences & Mean \pm SD & 0.712 & \pm & 0.364 & 0.500 & \pm & 0.539 & & \\
\hline & Paired Test & $P$-value & \multicolumn{3}{|c|}{$0.001 *$} & \multicolumn{3}{|c|}{$0.049 *$} & & \\
\hline \multirow[t]{2}{*}{ P-1M } & Differences & Mean \pm SD & 0.450 & \pm & 0.374 & 0.471 & \pm & 0.541 & & \\
\hline & Paired Test & P-value & \multicolumn{3}{|c|}{$0.011^{*}$} & \multicolumn{3}{|c|}{0.061} & & \\
\hline \multirow[t]{2}{*}{ P-3M } & Differences & Mean \pm SD & 0.414 & \pm & 0.521 & 0.250 & \pm & 0.528 & & \\
\hline & Paired Test & P-value & \multicolumn{3}{|c|}{0.080} & \multicolumn{3}{|c|}{0.299} & & \\
\hline \multirow[t]{2}{*}{ P-6M } & Differences & Mean \pm SD & 0.414 & \pm & 0.521 & 0.350 & \pm & 0.373 & & \\
\hline & Paired Test & $P$-value & \multicolumn{3}{|c|}{0.080} & \multicolumn{3}{|c|}{0.070} & & \\
\hline
\end{tabular}

*statistically significant at 0.05 level of significant 


\section{Maximal mouth opening:}

(Table 2) The frequency of dislocation per week was recorded for each patient in both groups at each follow up period. Pre injection Group (I): Two patients $(25 \%)$ had 6 episodes of dislocation per week, two patients $(25 \%)$ had 5 episodes of dislocation per week and four patients $(50 \%)$ had 4 episodes of dislocation per week. The mean value was (4.75) and standard deviation was (0.71). Group (II) Two patients $(25 \%)$ had 6 episodes of dislocation per week, three patients (37.5\%) had 5 episodes of dislocation per week and three patients $(37.5 \%)$ had 4 episodes of dislocation per week. The mean value was (4.875) and standard deviation was $(0.835)$. There was no statistically significant difference between the two groups at pre injection follow up period. $75 \%$ of all patients in both groups was treated with only single injection and didn't suffer from another episode of dislocation. One patient in group (I) and three patients in group (II) suffered other episodes of dislocation and needed second injection.

Table 2: showing statistical analysis of frequency of dislocation per week in both groups.

\begin{tabular}{|c|c|c|c|c|c|}
\hline \multirow{2}{*}{\multicolumn{2}{|c|}{ Frequency of dislocation }} & \multicolumn{2}{|c|}{ Groups } & \multicolumn{2}{|c|}{ T-Test } \\
\hline & & Group I & Group II & $\mathrm{t}$ & $P$-value \\
\hline \multirow{2}{*}{ Pre } & Range & $4-6$ & $4-6$ & \multirow{2}{*}{-0.32} & \multirow{2}{*}{0.751} \\
\hline & Mean \pm SD & $4.7 \pm 0.7$ & $4.8 \pm 0.8$ & & \\
\hline \multirow{2}{*}{2 Weeks } & Range & $0-2$ & $0-3$ & \multirow{2}{*}{1.96} & \multirow{2}{*}{0.069} \\
\hline & Mean \pm SD & $0.25 \pm 0.7$ & $0.62 \pm 1.06$ & & \\
\hline \multirow{2}{*}{1 Month } & Range & 0 & 0 & \multirow{2}{*}{0} & \multirow{2}{*}{0} \\
\hline & Mean \pm SD & $0 \pm 0$ & $0 \pm 0$ & & \\
\hline \multirow{2}{*}{3 Months } & Range & 0 & 0 & \multirow{2}{*}{0} & \multirow{2}{*}{0} \\
\hline & Mean \pm SD & $0 \pm 0$ & $0 \pm 0$ & & \\
\hline \multirow{2}{*}{6 Months } & Range & 0 & 0 & \multirow{2}{*}{0} & \multirow{2}{*}{0} \\
\hline & Mean \pm SD & $0 \pm 0$ & $0 \pm 0$ & & \\
\hline
\end{tabular}

\section{DISCUSSION}

According to Shakya et al., (2010) ${ }^{[19]}$ and akinabami $(2011)^{[20]}$ "The more complex and invasive method of treatment may not necessarily offer the best option and outcome of treatment, therefore conservative approaches should be exhausted and utilized appropriately before adopting the more invasive surgical techniques". They also stated that prolotherapy has the least side effects compared to other injection materials like sclerosing agent injection and autologous blood injection. Accordingly In this study we selected minimally invasive prolotherapy for treatment of TMJ chronic recurrent dislocation.

Dextrose initiates that process by inducing inflammatory response, stimulating the production of fibroblasts. At the same time Akinbami (2011) ${ }^{[20]}$ and Ungor et al., (2013) ${ }^{[21]}$ discussed that dextrose is the most common proliferant used in prolotherapy as it has the advantage of being readily available, inexpensive when compared with other proliferants, and has a high safety profile hence, we selected it in our study.

A wide variety of dextrose concentrations have been used with varying degrees of success, Refai et al., $(2011)^{[12]}$ and Reeves et al., $(2000)^{[22]}$ used 10\% dextrose concentration in prolotherapy, Topol et al.,(2005) ${ }^{[23]}$ used $12.5 \%$ dextrose concentration in prolotherapy, Rabago et al.,(2012) ${ }^{[16]}$ used $15 \%$ dextrose concentration, Majumdar et al., (2017) $)^{[24]}$ used $25 \%$ dextrose prolotherapy, Kiliç et al., (2016) ${ }^{[25]}$ used $30 \%$ dextrose concetration while Zhou et al., (2014) ${ }^{[13]}$ used 50\% desxtrose prolotherapy. Hakala et al ., $(2010)^{[26]}$ believed that the precise concentration of dextrose is not critical so long as it is strongly hypertonic and causes adequate cell wall lysis to attract fibroblasts and begin the regenerative process. They reported that dextrose concentration of more than $10 \%$ works partly by inflammation. In this study we selected $25 \%$ dextrose as recommended by Majumdar et al., (2017) ${ }^{[24]}$ who founded that $25 \%$ dextrose concentration had a promising results.

Dextrose prolotherapy had been injected in different injection sites for the purpose of management of TMJ dislocation. Refai et al., (2011) ${ }^{[12]}$ injected into three sites superior capsular attachment on the lateral margin of the glenoid fossa, inferior capsular attachment on the condylar neck, and the superior joint space and they reported that injection of dextrose in the superior joint space stabilize the joint and prevent dislocation. Kiliç et al., (2016) ${ }^{[25]}$ injected into five sites: posterior disk attachment, superior joint space, superior and inferior capsular attachments, and stylomandibular ligament. Zhou et al., (2014) ${ }^{[13]}$ and Majumdar et al., (2017) ${ }^{[24]}$ adopted single site of injection into posterior articular tissue into retro-discal ligament and they hypothesized that recurrent dislocation of the TMJ occurs mainly because of the laxity of the ligament and speculated that retrodiscal connective tissues might play an essential part in the control of hypermobility of the condyle.

Accordingly the idea of this study was evoked to compare between injection of dextrose prolotherapy in the superior joint space which has been considered to be an essential site for interventional treatment of recurrent dislocation and it's injection in the retrodiscal tissue in the treatment of recurrent temporomandibular joint dislocation 
and whether any of the injection has uncontrolled results which leads to limitation of mouth opening or not.

All patients of this study tolerated the TMJ prolotherapy injection well without serious complications and this was in consistence with the findings of Refai et al., (2011) ${ }^{[12]}$. On the other hand, although Zhou et al., (2014) ${ }^{[13]}$ agree with our findings of no serious complication, they reported one case of fainting and they related this to the patient anxiety.

In this study, discomfort after injection of dextrose prolotherapy was recorded in VAS for each follow up periods for all patients, the patients experienced mild to severe pain at first 2- 3 days post injection which was controlled by acetaminophen and resolve spontaneously after 1 week post injection.

In our study the maximal mouth opening showed decrease after prolotherapy injection for both groups without statistically significant difference but this was recovered within one month. This is in consistence with the results achieved by Zhou et al., (2014) ${ }^{[13]}$ who reported that the maximal mouth opening show insignificant reduction but patients who were given bilateral injections described a temporary decrease in maximal mouth opening during the first week which was recovered within one month. On the other hand this was in contrast to the finding of Refai et al., $(2011)^{[12]}$ who reported significant decrease in maximal mouth opening in all patients during the different follow up periods. This may be due to injection in additional two sites than our study (superior capsular attachment and inferior capsular attachment).

In the present study $75 \%$ of all patients in both groups were satisfied with the results after single injection as there was improvement regarding dislocation frequency except case No. (6) in group (I) and cases No. $(3,4,5)$ in group (II) which experience another episodes of dislocation and needed second injection. In in group (I) only one case $(12.5 \%$ of the patients) experienced dislocation after single injection at two weeks-post injection follow up period which required a second injection. This was in contradiction with the findings of Zhou et al., (2014) $)^{[13]}$, who reported that 35.5\% of the cases had another episodes of TMJ dislocation which necessitate second and third injections for improvement. This may be due to that twenty-one patients $(47 \%)$ in their study took ibuprofen to control the mild pain after injection. In group (II) three cases (37.5\% of the patients) experienced another episode of TMJ dislocation after single injection at two weeks-post injection follow up period which required a second injection. This was in contradict with the findings of Refai et al., $(2011)^{[12]}$, who recommended series of 4 times of injection of dextrose prolotheraby to stop TMJ dislocation but this may be because in Refai's study they inject only $1 \mathrm{ml}$ dextrose in the superior joint space unlike our study we injected $2 \mathrm{ml}$ dextrose in superior joint space in group II.

\section{REFERENCES}

1. Torres DE, McCain JP. Arthroscopic electrothermal capsulorrhaphy for the treatment of recurrent temporomandibular joint dislocation. Int J Oral Maxillofac Surg. 2012;41(6):681689doi:10.1016/j.ijom.2012.03.008.

2. Baur DA, Jannuzzi JR, Mercan U, Quereshy FA. Treatment of long term anterior dislocation of the TMJ. Int J Oral Maxillofac Surg. 2013;42(8):10301033. doi:10.1016/j.ijom.2012.11.005.

3. Aquilina P, Vickers R, McKellar G. Reduction of a chronic bilateral temporomandibular joint dislocation with intermaxillary fixation and botulinum toxin $\mathrm{A}$. Br J Oral Maxillofac Surg. 2004;42(3):272273-. doi:10.1016/j. bjoms.2004.01.010.

4. Matsushita K, Abe T, Fujiwara T. OK432 (Picibanil) sclerotherapy for recurrent dislocation of the temporomandibular joint in elderly edentulous patients: Case reports. $\mathrm{Br}$ J Oral Maxillofac Surg. 2007;45(6):511513doi:10.1016/j.bjoms.2006.09.002.

5. Machon V, Abramowicz S, Paska J, Dolwick MF. Autologous Blood Injection for the Treatment of Chronic Recurrent Temporomandibular Joint Dislocation. J Oral Maxillofac Surg. 2009;67(1):114119-. doi:10.1016/j. joms.2008.08.044.

6. Daif ET. Autologous blood injection as a new treatment modality for chronic recurrent temporomandibular joint dislocation. Oral Surgery, Oral Med Oral Pathol Oral Radiol Endodontology. 2010;109(1):3136-. doi:10.1016/j. tripleo.2009.08.002.

7. Oztel M, Bilski WM, Bilski A. Botulinum toxin used to treat recurrent dislocation of the temporomandibular joint in a patient with osteoporosis. $\mathrm{Br} \mathrm{J}$ Oral Maxillofac Surg. 2017;55(1):e1-e2. doi:10.1016/j. bjoms.2016.05.012.

8. Mayrink G, Olate S, Assis A, Sverzut A, De Moraes M. Recurrent mandibular dislocation treated by eminectomy. J Craniofac Surg. 2012;23(5). doi:10.1097/SCS.0b013e31825ab523.

9. Puelacher WC, Waldhart E. Miniplate eminoplasty: a new surgical treatment for TMJ-dislocation. J Cranio-Maxillofacial Surg. 1993;21(4):176178-. doi:10.1016/S101080109-(05)5182-X.

10. Güven O. Management of chronic recurrent temporomandibular joint dislocations: a retrospective study. J Craniomaxillofac Surg. 2009;37(1):2429-. doi:10.1016/j.jcms.2008.08.005. 
11. Hakala R V. Prolotherapy (proliferation therapy) in the treatment of TMD. Cranio. 2005;23(4):283288. doi:10.1179/crn.2005.040.

12. Refai H, Altahhan O, Elsharkawy R. The efficacy of dextrose prolotherapy for temporomandibular joint hypermobility: a preliminary prospective, randomized, double-blind, placebocontrolled clinical trial. J Oral Maxillofac Surg. 2011;69(12):29622970-. doi:10.1016/j. joms.2011.02.128.

13. Zhou $\mathrm{H}, \mathrm{Hu} \mathrm{K}$, Ding $\mathrm{Y}$. Modified dextrose prolotherapy for recurrent temporomandibular joint dislocation. $\mathrm{Br} \mathrm{J}$ Oral Maxillofac Surg. 2014;52(1):6366-. doi:10.1016/j. bjoms.2013.08.018.

14. Trescot A. Everything old is new again: New developments in prolotherapy. Tech Reg Anesth Pain Manag. 2015;19(118-14:(2-. doi:10.1053/j. trap.2016.09.003.

15. Nascimento MM, Vasconcelos BC, Porto GG, Ferdinanda G, Nogueira CM, Raimundo R de C. Physical therapy and anesthetic blockage for treating temporomandibular disorders: A clinical trial. Med Oral Patol Oral Cir Bucal. 2013;18(1). doi:10.4317/medoral.17491.

16. Rabago D, Zgierska A, Fortney L, et al. Hypertonic Dextrose Injections (Prolotherapy) for Knee Osteoarthritis: Results of a Single-Arm Uncontrolled Study with 1-Year Follow-Up. J Altern Complement Med. 2012;18(4):408414-. doi:10.1089/acm.2011.0030.

17. Jeelani S, Krishna S, Reddy J, Medicine VRD and O, 2013 undefined. Prolotherapy in temperomandibular disorders: an overview. hrpub.org.

18. Zhang W, Jones A, Doherty M. Does paracetamol (acetaminophen) reduce the pain of osteoarthritis?: A meta-analysis of randomised controlled trials. Ann Rheum Dis. 2004;63(8):901907-. doi:10.1136/ard.2003.018531.
19. Shakya S, Ongole R, Sumanth KN, Denny CE. Chronic bilateral dislocation of temporomandibular joint. Kathmandu Univ Med J. 2010;8(30):251256. doi:10.10167-90022(86)4356-0266/.

20. Akinbami BO. Evaluation of the mechanism and principles of management of temporomandibular joint dislocation. Systematic review of literature and a proposed new classification of temporomandibular joint dislocation. Head Face Med. 2011;7(1):10. doi:10.1186160-1746/X-710-.

21. Ungor C, Atasoy KT, Taskesen F, et al. Shortterm results of prolotherapy in the management of temporomandibular joint dislocation. J Craniofac Surg. 2013;24(2):411415-. doi:10.1097/ SCS.0b013e31827ff14f.

22. Reeves KD, Hassanein K. Randomized prospective double-blind placebo-controlled study of dextrose prolotherapy for knee osteoarthritis with or without ACL laxity. Altern Ther Health Med. 2000;6(2):6880-

23. Topol GA, Reeves KD, Hassanein KM. Efficacy of dextrose prolotherapy in elite male kickingsport athletes with chronic groin pain. Arch Phys Med Rehabil. 2005;86(4):697702-. doi:10.1016/j. apmr.2004.10.007.

24. Majumdar SK, Krishna S, Chatterjee A, Chakraborty R, Ansari N. Single Injection Technique Prolotherapy for Hypermobility Disorders of TMJ Using $25 \%$ Dextrose: A Clinical Study. J Maxillofac Oral Surg. 2017;16(2):226230. doi:10.1007/s126630-0944-016-.

25. Cömert Kiliç S, Güngörmüş $M$. Is dextrose prolotherapy superior to placebo for the treatment of temporomandibular joint hypermobility? A randomized clinical trial. Int J Oral Maxillofac Surg. 2016;45(7):813819-. doi:10.1016/j. ijom.2016.01.006.

26. Hakala R, Prolotherapy KL-J of, 2010 undefined. The use of prolotherapy for temporomandibular joint dysfunction. journalofprolotherapy.com. 